\title{
An Automated System for Stock Market Trading Based on Logical Clustering
}

\author{
Aleksandar RAKIĆEVIĆ, Vlado SIMEUNOVIĆ, Bratislav PETROVIĆ, Sanja MILIĆ
}

\begin{abstract}
In this paper a novel clustering-based system for automated stock market trading is introduced. It relies on interpolative Boolean algebra as underlying mathematical framework used to construct logical clustering method which is the central component of the system. The system uses fundamental analysis ratios, more precisely market valuation ratios, as clustering variables to differentiate between undervaluated and overvaluated stocks. To structure investment portfolio, the proposed system uses special weighting formulas which automatically diversify investment funds. Finally, a simple trading simulation engine is developed to test our system on real market data. The proposed system was tested on Belgrade Stock Exchange historical data and was able to achieve a high rate of return and to outperform the BelexLine market index as a benchmark variable. The paper has also provided in-depth analysis of the system's investment decision making process which reveals some exciting insights.
\end{abstract}

Keywords: automated trading system; fundamental analysis; linterpolative Boolean algebra; ogical clustering; stock market

\section{INTRODUCTION}

Financial markets are complex and dynamic environments influenced by many economic and noneconomic factors [1], both deterministic and random in nature [2]. Markets are non-linear systems governed by noise and uncertainty. Hence, to model and study these systems one needs to consider tools and techniques that can efficiently deal with non-linearity, noise and uncertainty. Vanstone and Finnie [3] claim that soft computing is precisely amongst these techniques.

The two most commonly used quantitative approaches for investment analysis in financial markets are technical and fundamental analysis. Technical analysis (TA) seeks to construct mathematical indicators using available market information (price, volume, bid, ask, spread etc.) in order to discover potential investment opportunities. Since the market information is changing rapidly, TA is regarded as the short-term toll. Some of the most influential studies that investigate usefullnes and effects of TA application in financial market trading are [4-11].

On the other hand, fundamental analysis (FA) uses financial ratios as a tool to analyze company's financial statements and discover profit opportunities. This approach is regarded as a long-term investment tool and is much less applied in the literature. Some of the most cited works on this subject are [12-17]

Automated trading, represents trading of stocks or other financial instruments in a computerized manner using an automated trading system (ATS) to make trading decisions and place the orders on the market. This kind of trading is also known as algorithmic trading or computerized investing. Automated trading was developed during the end of 1980s and the start of 1990s, with the expansion of information-communication technologies. It became very popular during 2000s, increasing its trading activity threefold in a few years - from $25 \%$ of total trading volume in 2005 to $75 \%$ until 2009 [18]. Today, automation and speed of the trading process are important dimensions of financial market design [19].

In recent years, soft computing methods are being increasingly used for development of systems which are able to analyze market information and make trading decisions. Fuzzy and other multi-valued logics, as a part of soft computing methods, are non-linear in nature and therefore can be successfuly used for modeling financial markets. Further are reviewed some of the numerous studies proposing logic-based systems for authomated/ algorithmic trading in financial markets.

Dourra and Siy [20] were among the first who applied fuzzy logic in financial market trading. They built a fuzzy system for authomated stock market trading based on technical analysis and prooved its succesfulness on real historical data. Lee et al. [21] proposed a knowledge-based trading system with fuzzy-based recognition method of graphical price patterns for financial prediction and making trading decisions. In [22], a complex Takagi-Sugeno-Kang type fuzzy rule based system was developed for stock price prediction in Taiwan Stock Exchange.

An interval type-2 fuzzy system for stock price prediction was presented in [23]. Authors conclude the system has shown superiority with respect to robustness, flexibility and error minimization and propose its usage in pricing financial derivatives and market trading. Two fuzzy systems for stock market trading were developed in [24]. The first was based on a special adaptation of the socalled "Logic-motivated fuzzy logic operators" approach, while the second one was based on newly proposed fuzzy Dempster-Shafer rules and it outperformed the previos.

Fong et al. [25] conducted examination of several trend-following algorithms based on different trend indicators, fuzzy controller and specially designed trend recalling system. In [26] authors propose an uncertainty reduction approach based on fuzzy logic to address problems of market timing and order size in technical trading. Their results showed improvement in profitability of existing strategies on highly volatile days when market risk is particulary high.

In the most recent study, Dymova and Sevastjanov [27] have found that the traditional fuzzy logic rules lose important information when dealing with the intersecting fuzzy classes and proposed new approach to the rule-base evidential reasoning. Their approach was succesfully tested within the trading system in foreign exchange trading. There are also many hybrid methodologies that incorporate fuzzy or some other kind of logic within the systems for authomated/algorithmic trading. Some of them are [28-30]. 
In this study, we develop a logic-based system for automated stock market trading. The proposed trading system is based on clustering method with logic-based measure of dissimilarity. We use interpolative Boolean algebra as a framework for implementation of consistent real-valued (fuzzy) logic. The proposed system uses market valuation ratios to cluster companies in order to discover groups of potentially undervalued stocks. Further, we introduce portfolio weighting formula as an extension of clustering component to enable full automatizaton of the portfolio construction process. The trading system is tested using Belgrade Stock Exchange market data and its performance compared to passive investment strategy which replicates performance of BelexLine index.

The proposed logical clustering method is a relatively new methodology, first time being used in this study to build an automated trading system. Therefore, it presents a step forward in current scientific literature. Furthermore, our findings may provide important information to investors and those researchers studying efficiencies of financial markets.

The rest of this paper is organized as follows. The next section presents a short overview of interpolative Boolean algebra - the main modelling technique used in this study. In the same section we give a brief overview of logical clustering method. Detailed explanation of the trading system's structure is provided in Section 3. Further, Section 4 presents test data, performance measure and benchmark variable, obtained results and corresponding discussion. Finally, Section 5 concludes the paper and considers some ideas for further work.

\section{INTERPOLATIVE BOOLEAN ALGEBRA}

Interpolative Boolean algebra (IBA) is a consistent $[0,1]$-valued realization of finite Boolean algebra (BA) first introduced in [31]. It is consistent with a sense that it preserves all three traditional laws of thought (identity, non-contradiction, excluded middle). IBA is used as a basis for consistent real-valued logic that can compensate the shortcomings of conventional fuzzy and multi-valued logics which are not in the Boolean framework.

IBA is based on the principle of structuralfunctionality (SF). Unlike the truth-functionality (TF) principle, the SF principle focuses on the structure of IBA elements instead of its values. Furthermore, SF allows us to map any Boolean functions into its corresponding generalized Boolean polynomials (GBP) homomorphicly. This mapping is realized through the transformation rules presented in [32-34].

GBP represents the middle layer in the process of transformation from logical to arithmetic expression. It is a polynomial that consists of BA elements as variables, standard algebraic operators $\{+,-\}$ and generalized product $\otimes$. Generalized product (GP) is an operator that satisfies all four axioms of t-norms (commutativity, associativity, monotonicity and boundary condition) and the additional non-negativity condition [35]. It can be any function from the following interval:

$$
\max (0, a+b-1) \leq a \otimes b \leq \min (a, b) .
$$

In order to obtain arithmetic expression from GBP one needs to choose an appropriate GP operator. The selection of GP operator depends on the nature of the attributes within logical expression. There are three marginal cases:

- The case when attributes are of the same/similar nature (analogous to positive correlation in statistics), the $\mathrm{min}$ function is applied;

- The case when the nature of attributes is inverse (analogous to negative correlation in statistics), Lukasiewicz operator is proposed;

- And finally, the case when attributes are of different nature (analogous to statistical independence), ordinary product is used as the operator of GP

In summary, IBA theory gives us the tool to evaluate any logical expression in real [0,1]-valued framework consistent with traditional laws of thought. It allows us to build a whole new generation of intelligent algorithms, methods and machines, and to extend the scope of the problems we are able to solve. So far, IBA has been applied in logical aggregation for equity selection [36], the evaluation of companies' financial performances [37-39], energy management [40], multi-criteria decision making [41], multi-expert decision making [42] and logical neural networks [43]. The corresponding software support for IBA-based LA is introduced in [44].

\subsection{Logical Clustering}

Clustering, is a method to extract knowledge about the hidden structures in the data or partition it into groups (clusters) without any previous knowledge nor experience about it [45]. The essence of each clustering method is the way we compare objects. Objects are compared with respect to their positions, characteristics or behavior. There is no universal measure able to consider different aspects of proximity. Instead, one must choose an appropriate one from the wide set of different measures of distances, similarity/dissimilarity or correlation. Many of them are summarized in [46].

Logical clustering (LC), first introduced in [47], is a clustering technique based on a logical measure of proximity. It uses a logic-based measure of similarity/dissimilarity within the basic clustering algorithm to cluster objects according to their features. In LC approach, dissimilarity between objects is measured using an interpolative relation of exclusive disjunction, which is a logical function with $[0,1]$ value realization based on IBA. Interpolative relation of exclusive disjunction satisfies all necessary conditions in order to be used as a measure of dissimilarity. The corresponding proof is first presented in [48] and later published in [45].

Exclusive disjunction (XOR) between two objects in regard to one observed characteristic is defined as the following relation:

$$
A \underline{\vee} B=\left(A \cap B^{c}\right) \cup\left(A^{c} \cap B\right) .
$$

It is a complementary relation to the equivalence relation:

$$
A \underline{\vee} B=1-(A \Leftrightarrow B) .
$$


Using IBA one can construct consistent real-valued relations - the so-called interpolative relation [49]. Implementing IBA theory in XOR relation we obtain interpolative XOR. This is done using transformation rules detaily explained in [50]. The following Eq. (4) shows the corresponding GBP for interpolative XOR relation:

$$
\begin{aligned}
(A \underline{\vee} B)^{\otimes} & =(A \wedge \neg B) \vee(\neg A \wedge B)^{\otimes}(x) \\
& =A(x)+B(x)-2 A(x) \otimes B(x) .
\end{aligned}
$$

In order to obtain arithmetic expression from this GBP, generalized product $\otimes$ has to be replaced with an appropriate T-norm, which is in this case the min function:

$$
\begin{aligned}
(A \underline{\vee} B)^{\otimes} & =A(x)+B(x)-2 A(x) \otimes B(x) \\
& =A(x)+B(x)-2 \min \{A(x), B(x)\}
\end{aligned}
$$

A precondition to perform LC is to transform attributes' values (raw data) into $[0,1]$ logical values:

$\|\bullet\|: \Omega \rightarrow[0,1]$

Afterwards, one can calculate dissimilarity over resulting values using Eq. (5).

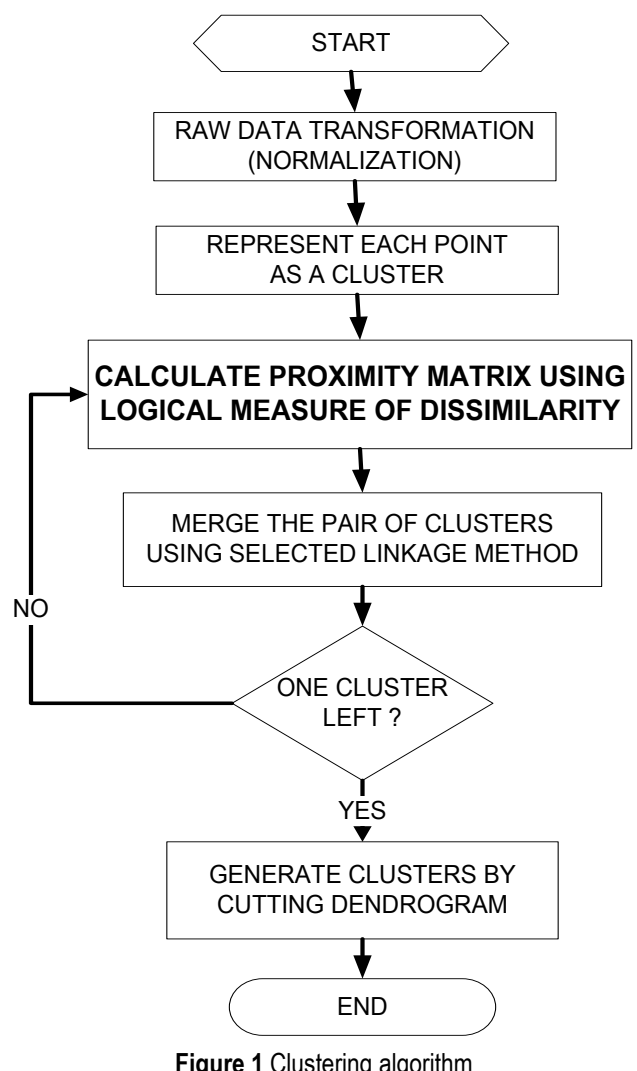

In this study we use agglomerative hierarchical approach to logical clustering. This approach has been already applied for clustering countries according to their macroeconomic fundamentals [45]. Fig. 1 presents the algorithm for logical clustering.

\section{THE PROPOSED SYSTEM}

In this study, we propose a novel ATS for stock market trading. The proposed system employs logic-based clustering method to group stocks based on the selected investment ratios and to select those clusters that are appropriate for investment. It is a complex system consisted of three components: pre-processing, financial analysis and portfolio construction component. In order to test our ATS we build a simple engine to simulate real market trading. In Fig. 2 we present the structure of the proposed system and its interaction with simulation engine. In the following parts of this section we will give a detailed explanation of the components.

\subsection{Data Normalization Component}

As it can be seen in clustering algorithm presented in Fig. 1, to apply logical clustering one needs to transform raw data into logical values. To perform this transformation function that maps raw values into $[0,1]$ value interval. In this study, we use the standard max-min normalization function for this purpose:

$$
X_{n o r m}=\frac{X-\min (X)}{\max (X)-\min (X)}
$$

It is important to note that the max and min values are assigned after removal of extreme values from both ends of the raw data interval.

\subsection{Clustering Component}

Clustering component is the one that enables our ATS to analyze stocks and seeks for profit opportunities. It groups stocks based on market valuation ratios, using average ratio values within groups to separate favorable clusters.

The proposed ATS uses logic-based approach to clustering explained in Section 2.1. Using the interpolative relation of exclusive disjunction, more exactly its arithmetic form presented in Eq. (5), LC is able to extract dissimilarities between companies according to their market value characteristics and group similar companies into the clusters. Furthermore, clusters with potentially undervalued companies are identified using the average value of ratios within the cluster. Finally, investment strategy considers buying undervaluated stocks and selling those categorized as overvaluated.

Market valuation ratios are indicators used by investors to estimate the attractiveness of a potential investment. These ratios relate firms' market value (market capitalization) with the main categories from their financial statement such as shareholders' equity, net profit, sales, etc. In this study, we use three main ratios as an indication of market value of the company. Detailed description of the ratios is presented in Tab. 1 .

The trading logic of the system is to differentiate between overvaluated and undervaluated stocks using the valuation ratios described in Tab. 1. An overvaluated stock is the one with the excessive value assigned by the market. This value is reflected in high current price of the stock that 
cannot be justified by company's financials (income statement, balance sheet and statement of cash flow). By analogy, undervaluated stock is the one that is actually worth more than it is currently trading. Overvaluation and undervaluation are often result of irrational (emotional) behaviour of investors. There is a whole area of finance dealing with this phenomenon called [51].

\begin{tabular}{|c|c|c|}
\multicolumn{2}{|c|}{ Table 1 Market valuation ratios } \\
\hline Ratio & Label & Formula \\
\hline Price per earnings & PE & $\frac{\text { Market capitalization }}{\text { Net earnings }}$ \\
\hline Price per book & PB & $\frac{\text { Market capitalization }}{\text { Shareholders' equity }}$ \\
\hline Price per sales & PS & $\frac{\text { Market capitalization }}{\text { Total revenue }}$ \\
\hline
\end{tabular}

In this study, we use earnings outlook (PE), income outlook (PS) and book value of equity (PB) to valuate stocks. Using average values of these ratios calculated within clusters, system is able to determine whether the cluster consists of overvaluated or undervaluated stocks. If the average values for all three ratios within cluster are high, the stocks within that cluster are considered overvaluated. Vice versa, the undervaluated cluster is the one that has low average values of all three ratios. To distinguish other non-marginal cases, we give the highest priority to $\mathrm{PE}$ ratio, then to $\mathrm{PB}$ and $\mathrm{PS}$ ratio. This means that if the company has low value of PE it is considered as undervaluated even when it has high values of both $P B$ and PS. Vice versa, high values of PE indicate overvaluated company regardless of the $\mathrm{PB}$ and PS.

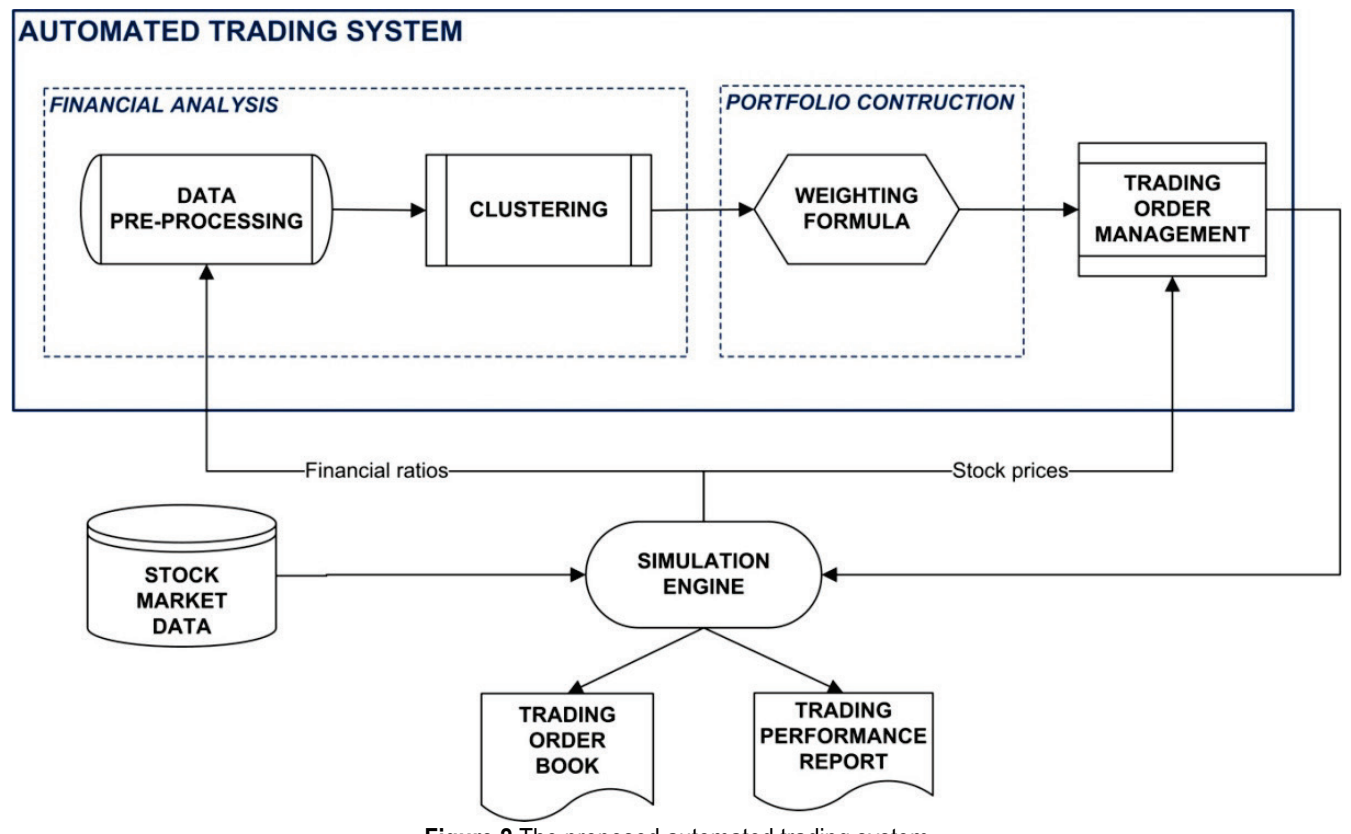

Figure 2 The proposed automated trading system

\subsection{Weighting Formula}

To enable our system to construct portfolio we introduce the weighting formula. First, the clustering component differentiates between undervaluated and overvaluated clusters of stocks. After the undervaluated stocks have been identified, the weighting formula is used to assign portfolio weight to each undervaluated stock. This weight represents the share of the funds (amount of money) that is going to be invested in the specific stock.

The proposed weighting formula is constructed to consider only the "prefereable clusters" (consisted of undervaluated stocks) and the number of stocks within. The investment funds are equally distributed between preferred clusters (there can be more than one preferred cluster as a result of clustering). Furthermore, each stock obtains the same share of cluster's funds. The following Eq. 8 presents the proposed weighting formula:

$w_{t}^{i}=\frac{\left(\frac{1}{K_{t}}\right)}{n_{t}^{k}}$, where $w_{t}^{i}$ is the $i$-th equity weight in portfolio in time $t, K_{t}$ is the number of preferable clusters obtained in time $t$, while $n_{t}^{k}$ stands for the number of securities selected for investment from cluster $k$ in time $t$.

The proposed weighting formula is dynamic, causing the changes in portfolio weights according to the changes in the number of preferred clusters and the number of stocks within.

\subsection{Trading Order Management}

This part of the system serves to create and manage trading orders. In other words, it executes the trading strategy on the market.

Each time the clustering and weighting formula is run new investment portfolio is constructed. The task of the trading order management component is to determine differences compared to the old portfolio and to create trading orders according to these differences. This means that some positions in portfolio will be set for sale, some to be bought, while for most of them trading orders will be 
created to adjust portfolio weights according to the new structure of portfolio.

\subsection{Simulation Engine}

To make a credible test of our ATS we build a simple engine aimed to simulate real stock market trading. In the simulation engine, we do not include potential transaction costs. Further, the short selling ${ }^{1}$ of stocks is also excluded which reflects the rules of the Belgrade Stock Exchange the market that is used to obtain simulation results.

Simulation engine works as follows:

1) ATS communicates with the simulation engine to obtain financial data. Simulation engine retrieves the data from stock market database (DB) and sends them to ATS.

2) Financial data are received by the pre-processing component where transformation to corresponding logical values is performed. Further, the obtained values are forwarded to the clustering component for analysis. After cluster analysis, the weighting formula is applied to construct/update investment portfolio.

3) When new portfolio is constructed, the ATS uses trading order management component to interact with simulation engine to simulate real market trading. Simulation engine accesses DB to obtain transaction prices and sends the trading confirmation to the system. Finally, it makes a new transaction record within the trading order book and calculates performance measures.

\section{SIMULATION RESULTS}

In this section we present and discuss results obtained in trading simulation.

\subsection{Data}

To simulate trading with the proposed ATS, we use real market and financial statement data from Belgrade Stock Exchange (BSE) ${ }^{2}$. We choose 29 actively traded stocks from BelexLine index basket. We exclude banks and insurance companies, since the methods for their valuation and analysis differ from the other companies. We use several years of monthly data, in a period from 1.6.2013 until 1.1.2017.

\subsection{Performance Measure}

To evaluate the successfulness of the proposed system we use the standard procedure for testing ATSs. The procedure is simple and consists of calculating some of the well known profitability measures and benchmarking it against the market performance $[7,9,10,20]$. To measure profitability of the proposed trading system we use return on investment (ROI):

$$
R O I_{t}=\frac{V_{t}-V_{t-1}}{V_{t-1}},
$$

\footnotetext{
${ }^{1}$ Short selling is the practice of selling stocks that are not being owned with an idea to repurchase them at lower price levels.
}

where $V_{t}$ stands for portfolio value in time $t$. Positive ROI indicates the trading was successful. However, additional benchmarking of the resulting ROE needs to be conducted. The following is the reason for this.

There are two basic types of investment management in stock markets: passive and active. In passive investment management the investor creates portfolio to replicate stock market index. Market index components and their weights are used to create an initial investment portfolio. Further, the investment strategy is to track changes in index structure and performs trading in order to maintain portfolio as the replication of the index structure. The idea is to ignore individual stocks and make profits on the movements of the market as a whole. This type of investment strategy does not require any kind of analytics effort and hence is timecostless. On the other hand, active investment management means active trading with associated time and money costs (analytics costs, commission costs etc.). In order to justify these costs, active investment management has to provide the strategy that is more successfull (profitable) than the simple market index replicating.

For this reason, the main benchmark for any trading system or strategy is the market index itself. And only if the system or strategy beats the market it is considered as successful and noteworthy. To benchmark our trading strategy, implemented within the proposed ATS, we use performances of the BelexLine index - the main market index of the Belgrade Stock Exchange.

\subsection{Results and Discussion}

Our system starts trading in June 2013 with an initial investment of one million Serbian dinars (RSD). At the beginning of each month the proposed ATS performs analysis, constructs new portfolio for the forthcoming month and performs reallocation of investment funds according to new weighting scheme.

The proposed ATS shows excellent performances during the several years of testing period. Not only has the system achieved positive ROI of $94,29 \%$, but it also managed to beat BelexLine index that achieved ROI of $56,46 \%$. Fig. 3 presents both ATS and Belex Line index performances during the test period. The graph shows that the ATS portfolio value was consistently higher than the BelexLine portfolio value.

Table 2 Simulation results

\begin{tabular}{|c|c|c|}
\hline & Belex Line & ATS \\
\hline Total profit & $56,46 \%$ & $94,29 \%$ \\
\hline \multirow{2}{*}{ Nmb of positive months } & 28 & 31 \\
\cline { 2 - 3 } & $65,12 \%$ & $72,09 \%$ \\
\hline \multirow{2}{*}{ Num of negative months } & 15 & 12 \\
\cline { 2 - 3 } & $34,88 \%$ & $27,91 \%$ \\
\hline AVG profit per month & $1,094 \%$ & $1,601 \%$ \\
\hline STD profit per month & 0,031 & 0,030 \\
\hline
\end{tabular}

During the test period of 43 months our system showed positive perfomances for 31 months and negative for only 12. In comparison, the BelexLine index had 28 positive and 15 negative months. Further statistics on these results are presented in Tab. 2. It is also important to note that the

${ }^{2}$ www.belex.rs 
average monthly profit of the system was $1,601 \%$ comparing to $1,094 \%$ achieved by the market index.

It is interesting to note that the test period can be divided into two different subperiods regarding system's performances. In the first half of the period (from June 2013 until January 2015) the system showed positive performance but was not able to significantly outperform the market index. However, in the second half of the test period (from January 2015 until January 2017) the system showed exciting performance and greatly surpassed the benchmark variable. Detailed analysis of these subperiods is presented in Tab. 3.

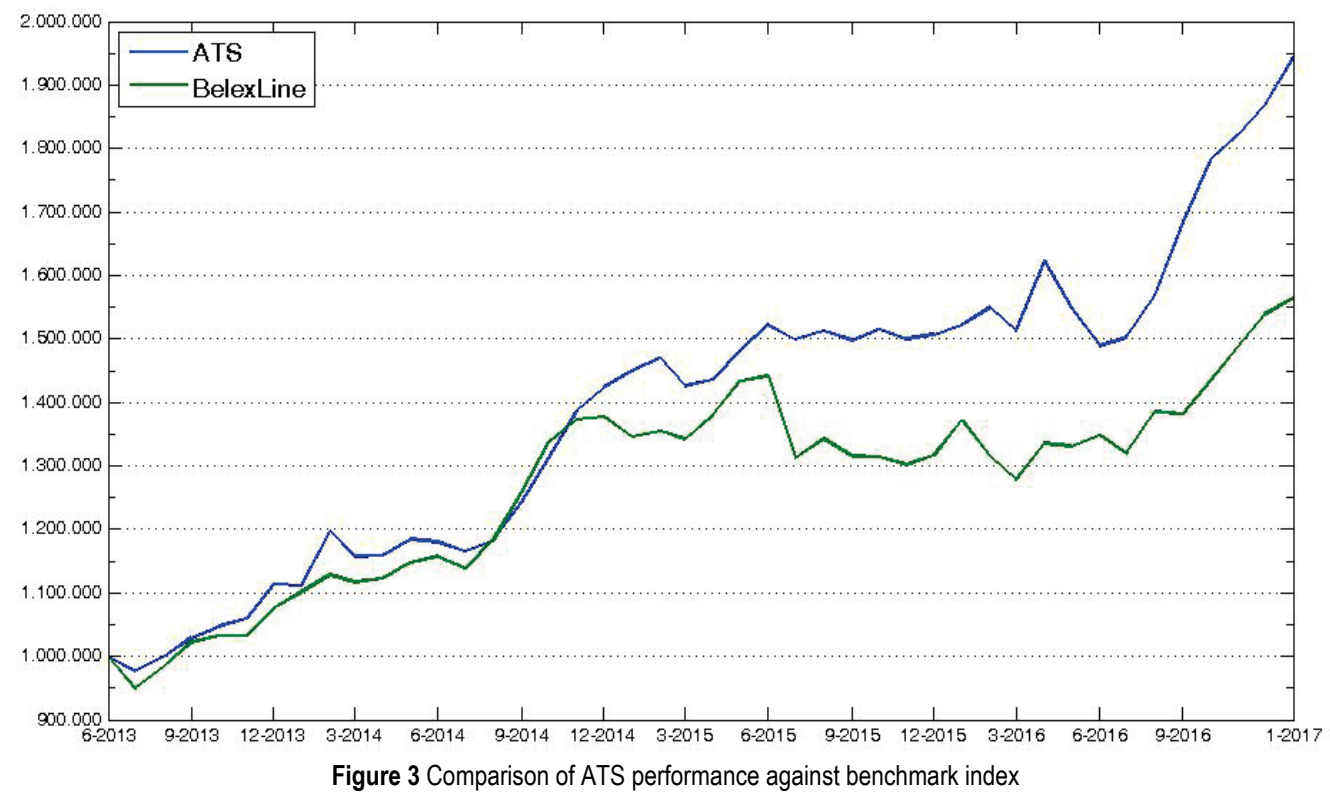

Table 3 Analysis of subperiod results

\begin{tabular}{|c|c|c|c|}
\hline & Performance measure & BelexLine & ATS \\
\hline \multirow{7}{*}{ 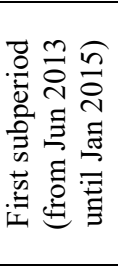 } & Total profit & $34,55 \%$ & $45,01 \%$ \\
\hline & \multirow{2}{*}{ Nmb of positive months } & 14 & 14 \\
\hline & & $73,68 \%$ & $73,68 \%$ \\
\hline & \multirow{2}{*}{ Num of negative months } & 5 & 5 \\
\hline & & $26,32 \%$ & $26,32 \%$ \\
\hline & AVG profit per month & $1,61 \%$ & $2,01 \%$ \\
\hline & STD profit per month & 0,029 & 0,029 \\
\hline \multirow{7}{*}{ 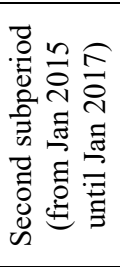 } & Total profit & $16,29 \%$ & $33,98 \%$ \\
\hline & \multirow{2}{*}{ Nmb of positive months } & 14 & 18 \\
\hline & & $58,33 \%$ & $75,00 \%$ \\
\hline & \multirow{2}{*}{ Num of negative months } & 10 & 6 \\
\hline & & $41,67 \%$ & $25,00 \%$ \\
\hline & AVG profit per month & $0,56 \%$ & $1,3 \%$ \\
\hline & STD profit per month & 0,032 & 0,031 \\
\hline
\end{tabular}

Further discussion of results requires deeper analysis of trading system's decisions and actions. To do this, we decompose system's decision making process (analysis and portfolio construction) for one specific point of time, observe its actions (trading order execution) and track upcoming market behaviour to asses consequences of these actions (performance of the portfolio in upcoming months). We randomly selected September of 2015 as a time point to perform this analysis.

In Tab. 4 we present clustering results obtained on the $1^{\text {st }}$ September 2015. Stocks are grouped in four clusters. Based on the average ratio values within clusters (centroids), clusters 1 and 4 were rated as undervaluated making them attractive for investing. Cluster 3 was rated as overvaluated, while cluster 2 obtained neutral rating. Out of total 29 companies analyzed by the ATS, six companies from cluster 1 and nine companies from cluster 4 were selected for portfolio.
Table 4 Summary of clustering results in September 2015

\begin{tabular}{|c|c|c|c|c|c|}
\hline Cluster & $\begin{array}{c}\text { Number } \\
\text { of stocks }\end{array}$ & $\begin{array}{c}\text { Avg } \\
\text { PE }\end{array}$ & $\begin{array}{c}\text { Avg } \\
\text { PS }\end{array}$ & $\begin{array}{c}\text { Avg } \\
\text { PB }\end{array}$ & Interpretation \\
\hline 1 & 6 & 0,11 & 0,08 & 0,23 & Undervaluated \\
\hline 2 & 12 & 1 & 0,09 & 0,29 & Neutral \\
\hline 3 & 2 & 1 & 0,83 & 0,44 & Overvaluated \\
\hline 4 & 9 & 0,29 & 0,67 & 0,66 & Undervaluated \\
\hline
\end{tabular}

From those 15 selected companies 13 were already in the portfolio since August 2015 and their stocks were rated as a "hold" in September 2015. There were also two newly selected companies whose stocks were rated with"buy" recommendation in September 2015, while two were rated as a "sell" in the same month. Finally, the weighting formula (Eq. 8) was employed to calculate portfolio weights (quantity of money to be invested in each of the selected stocks). The changes in the structure of portfolio at the beginning of September 2015 are presented in Tab. 5.

To investigate the quality of investment decisions made by our system, we mark all stocks that are either added or removed from portfolio in that specific point of time. Further, we track the price movements of those stocks in the upcoming months (Fig. 4) to investigate whether the specific decision to invest/disinvest was right or wrong.

On the $1^{\text {st }}$ September 2015IMPL and RDJZ were marked for investing, while GMON and VDAV for disinvesting. Fig. 3 shows price trends of these stocks in the forthcoming months, which enables us to check validity of these investment decisions. IMPL stocks, which were rated as a "buy" in September 2015, show impressive positive price performance starting from October 2015. On the other hand, GMON stocks were rated as a "sell" and negative price trendin the forthcoming months proves decision to disinvest. However, investing in RDJZ proves to be bad decision since the price performances are not in favour of decision to buy. Still, the negative effect of this investment was far more less 
than the positive effects of both IMPL and GMON. Finally, decision to sell VDAV turns out to have neutral effect on portfolio value since the price did not move for almost several months.

Table 5 Summary of clustering results in September 2015

\begin{tabular}{|c|c|c|c|c|c|}
\hline $\begin{array}{c}\text { Stock } \\
\text { symbol }\end{array}$ & $\begin{array}{c}\text { Old } \\
\text { portfolio }\end{array}$ & Cluster & Decision & Weight & $\begin{array}{c}\text { New } \\
\text { portfolio }\end{array}$ \\
\hline AERO & 90.358 & 4 & hold & $5,56 \%$ & 83.232 \\
\hline AGBC & 0 & 2 & - & - & 0 \\
\hline ALFA & 96.339 & 4 & hold & $5,56 \%$ & 83.232 \\
\hline BIPB & 0 & 2 & - & - & 0 \\
\hline BMBI & 84.424 & 4 & hold & $5,56 \%$ & 83.232 \\
\hline ENHL & 0 & 3 & - & - & 0 \\
\hline FITO & 96.861 & 4 & hold & $5,56 \%$ & 83.232 \\
\hline GFOM & 0 & 2 & - & - & 0 \\
\hline GMON & 111.181 & 2 & sell & - & 0 \\
\hline IMLK & 93.825 & 4 & hold & $5,56 \%$ & 83.232 \\
\hline IMPL & 0 & 1 & buy & $8,33 \%$ & 124.848 \\
\hline INSJ & 104.675 & 1 & hold & $8,33 \%$ & 124.848 \\
\hline JESV & 101.946 & 1 & hold & $8,33 \%$ & 124.848 \\
\hline LSTA & 0 & 2 & - & - & 0 \\
\hline MOIN & 108.063 & 1 & hold & $8,33 \%$ & 124.848 \\
\hline MTLC & 103.907 & 4 & hold & $5,56 \%$ & 83.232 \\
\hline NIIS & 106.262 & 1 & hold & $8,33 \%$ & 124.848 \\
\hline PLNM & 0 & 2 & - & - & 0 \\
\hline PLNN & 92.454 & 4 & hold & $5,56 \%$ & 83.232 \\
\hline PRGS & 0 & 3 & - & - & 0 \\
\hline RDJZ & 0 & 1 & buy & $8,33 \%$ & 124.848 \\
\hline SJPT & 106.133 & 4 & hold & $5,56 \%$ & 83.232 \\
\hline TETO & 0 & 2 & - & - & 0 \\
\hline TGAS & 83.953 & 4 & hold & $5,56 \%$ & 83.232 \\
\hline TIGR & 0 & 2 & - & - & 0 \\
\hline VBSE & 0 & 2 & - & - & 0 \\
\hline VDAV & 117.789 & 2 & sell & - & 0 \\
\hline VITL & 0 & 2 & - & - & 0 \\
\hline VZAS & 0 & 2 & - & - & 0 \\
\hline SUM & 1.498 .172 & & & $100 \%$ & 1.498 .172 \\
\hline
\end{tabular}

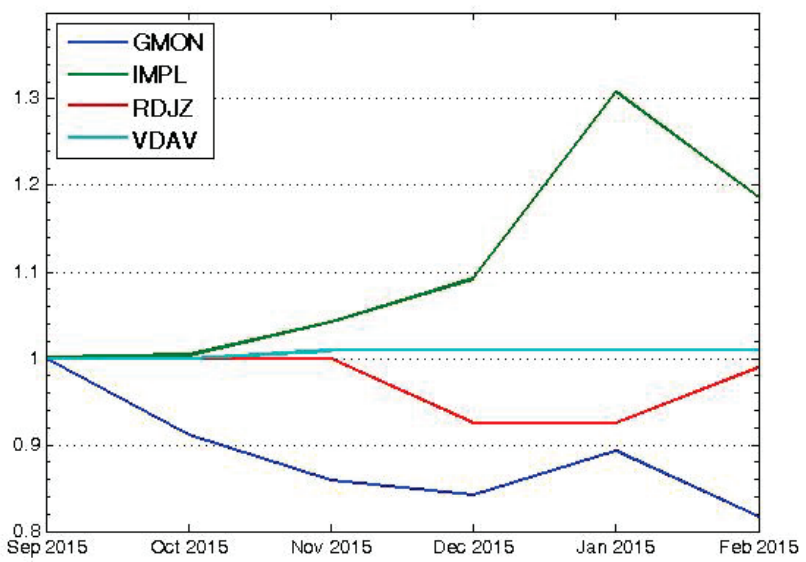

Figure 4 Selected stocks' performances from Sep 2015

This in-depth analysis reveals a satisfactory level of accuracy of investment decisions made by the system. Even in cases when investment decision lacks positive effects, realized losses are small. This testifies the credibility and reliability of the proposed ATS.

\section{CONCLUSION}

In this paper, we presented an automated trading system for stock market trading. The proposed system is a complex one, consisting of several components. It employs logicbased clustering method to analyze companies financials in order to differentiate between undervaluated and overvaluated stocks. The trading strategy employed by the system buys undervaluated and sells overvaluated stocks. Further, the system employs a specific weighting formula to structure investment portfolio. In order to test our system, we built a simple trading engine that enables simulation of real market trading.

The proposed system was able to create and manage an investment portfolio in an automated manner, achieving excellent performance during trading simulation test. Not only did it achieve a positive return on investment, but it also outperformed benchmark variable. Further in-depth analysis of individual trading decisions made by the system reveals sufficient level of accuracy and reliability in investment decision making.

We conclude that interpolative Boolean algebra, used as a basic logical framework in this study, enables us to model complex logical relations and expressions in a consistent manner (preserving traditional laws of thought). It proved to be useful in creating advanced techniques able to incorporate human-like reasoning into machines.

For further research, it would be interesting to test the proposed system in daily trading with transaction costs incorporated and short selling allowed. Furthermore, we will strive to supplement the system with technical analysis components able to analyze short term market conditions in order to investigate whether this will improve its investment performances.

\section{REFERENCES}

[1] Ballings, M., Poel, D. V. D., Hespeels, N., \& Gryp, R. (2015). Evaluating multiple classifiers for stock price direction prediction. Expert Systems with Applications, 34(1), 7046-7056. https://doi.org/10.1016/j.eswa.2015.05.013

[2] Chang, T. H. \& Wang, T. C. (2009). Using the fuzzy multicriteria decision making approach for measuring the possibility of successful knowledge management. Information Sciences, 179(4), 1970-1983. https://doi.org/10.1016/j.ins.2008.10.012

[3] Vanstone, B. \& Finnie, G. (2009). An empirical methodology for developing stockmarket trading systems using artificial neural networks. Expert Systems with Applications, 36(3), 6668-6680. https://doi.org/10.1016/j.eswa.2008.08.019

[4] Pruitt, S. W. \& White, R. E. (1988). The CRISMA trading system: Who says technical analysis can't beat the market? The Journal of Portfolio Management, 14(3), 55-58. https://doi.org/10.3905/jpm.1988.409149

[5] Brock, W., Lakonishok, J., \& LeBaron, B. (1992). Simple technical trading rules and the stochastic properties of stock returns. The Journal of Finance, 47(5), 1731-1764. https://doi.org/10.1111/j.1540-6261.1992.tb04681.x

[6] Bessembinder, H. \& Chan, K. (1995). The profitability of technical trading rules in the Asian stock markets. PacificBasin Finance Journal, 3(2), 257-284. https://doi.org/10.1016/0927-538X(95)00002-3

[7] Neely, C., Weller, P., \& Dittmar, R. (1997). Is technical analysis in the foreign exchange market profitable? A genetic programming approach. Journal of Financial and Quantitative Analysis, 32(4), 405-426. https://doi.org/10.2307/2331231

[8] Lo, A. W., Mamaysky, H., \& Wang, J. (2000). Foundations of technical analysis: Computational algorithms, statistical 
inference, and empirical implementation. The Journal of Finance, 55(4), 1705-1770. https://doi.org/10.1111/0022-1082.00265

[9] Hsu, P. H. \& Kuan, C. M. (2005). Reexamining the profitability of technical analysis with data snooping checks. Journal of Financial Econometrics, 3(4), 606-628. https://doi.org/10.1093/jjinec/nbi026

[10] Park, C. H. \& Irwin, S. H. (2007). What do we know about the profitability of technical analysis? Journal of Economic Surveys, 21(4), 786-826. https://doi.org/10.1111/j.1467-6419.2007.00519.x

[11] Bajgrowicz, P. \& Scaillet, O. (2012). Technical trading revisited: False discoveries, persistence tests, and transaction costs. Journal of Financial Economics, 106(3), 473-491. https://doi.org/10.1016/j.jineco.2012.06.001

[12] Ou, J. A. \& Penman, S. H. (1989). Financial statement analysis and the prediction of stock returns. Journal of Accounting and Economics, 11(4), 295-329. https://doi.org/10.1016/0165-4101(89)90017-7

[13] Lev, B. \& Thiagarajan, S. R. (1993). Fundamental information analysis. Journal of Accounting research, 31(2), 190-215. https://doi.org/10.2307/2491270

[14] Abarbanell, J. S. \& Bushee, B. J. (1997). Fundamental analysis, future earnings, and stock prices. Journal of Accounting Research, 35(1), 1-24. https://doi.org/10.2307/2491464

[15] Abarbanell, J. S. \& Bushee, B. J. (1998). Abnormal returns to a fundamental analysis strategy. The Accounting Review, 73(1), 19-45.

[16] Dechow, P. M., Hutton, A. P., Meulbroek, L., \& Sloan, R. G. (2001). Short-sellers, fundamental analysis, and stock returns. Journal of Financial Economics, 61(1), 77-106. https://doi.org/10.1016/S0304-405X(01)00056-3

[17] Malkiel, B. G. (2003). The efficient market hypothesis and its critics. The Journal of Economic Perspectives, 17(1), 5982. https://doi.org/10.1257/089533003321164958

[18] Kissell, R. (2013). The science of algorithmic trading and portfolio management. Academic Press, San Diego.

[19] Hendershott, T. \& Moulton, P. C. (2011). Automation, speed, and stock market quality: The NYSE's hybrid. Journal of Financial Markets, 14(4), 568-604. https://doi.org/10.1016/j.finmar.2011.02.003

[20] Dourra, H. \& Siy, P. (2002). Investment using technical analysis and fuzzy logic. Fuzzy Sets and Systems, 127(2), 221-240. https://doi.org/10.1016/S0165-0114(01)00169-5

[21] Lee, C. H. L., Liu, A., \& Chen, W. S. (2005). Pattern discovery of fuzzy time series for financial prediction. IEEE Transactions on Knowledge \& Data Engineering, 5, 613625.

[22] Chang, P. C. \& Liu, C. H. (2008). A TSK type fuzzy rule based system for stock price prediction. Expert Systems with applications, 34(1), 135-144. https://doi.org/10.1016/j.eswa.2006.08.020

[23] Zarandi, M. F., Rezaee, B., Turksen, I. B., \& Neshat, E. (2009). A type-2 fuzzy rule-based expert system model for stock price analysis. Expert Systems with Applications, 36(1), 139-154. https://doi.org/10.1016/j.eswa.2007.09.034

[24] Sevastianov, P. \& Dymova, L. (2009). Synthesis of fuzzy logic and Dempster-Shafer Theory for the simulation of the decision-making process in stock trading systems. Mathematics and Computers in Simulation, 80(3), 506-521. https://doi.org/10.1016/j.matcom.2009.06.027

[25] Fong, S., Si, Y. W., \& Tai, J. (2012). Trend following algorithms in automated derivatives market trading. Expert systems with applications, 39(13), 11378-11390. https://doi.org/10.1016/j.eswa.2012.03.048

[26] Gradojevic, N. \& Gençay, R. (2013). Fuzzy logic, trading uncertainty and technical trading. Journal of Banking \& Finance, 37(2), 578-586. https://doi.org/10.1016/j.jbankfin.2012.09.012
[27] Dymova, L., Sevastjanov, P., \& Kaczmarek, K. (2016). A Forex trading expert system based on a new approach to the rule-base evidential reasoning. Expert Systems with Applications, 51, 1-13. https://doi.org/10.1016/j.eswa.2015.12.028

[28] Kuo, R. J., Chen, C. H., \& Hwang, Y. C. (2001). An intelligent stock trading decision support system through integration of genetic algorithm based fuzzy neural network and artificial neural network. Fuzzy Sets and Systems, 118(1), 21-45. https://doi.org/10.1016/S0165-0114(98)00399-6

[29] Bagheri, A., Peyhani, H. M., \& Akbari, M. (2014). Financial forecasting using ANFIS networks with quantum-behaved particle swarm optimization. Expert Systems with Applications, 41(14), 6235-6250. https://doi.org/10.1016/j.eswa.2014.04.003

[30] Huang, H., Pasquier, M., \& Quek, C. (2009). Financial market trading system with a hierarchical coevolutionary fuzzy predictive model. IEEE transactions on Evolutionary Computation, 13(1), 56-70. https://doi.org/10.1109/TEVC.2008.911682

[31] Radojevic, D. (2000). New [0,1]-valued logic: A natural generalization of Boolean logic. Yugoslav Journal of Operations Research, 10(2), 185-216.

[32] Radojevic, D. (2008). Logical aggregation based on interpolative Boolean algebra. Mathware \& Soft Computing, $15,125-141$

[33] Radojevic, D. (2008). Real sets as consistent Boolean generalization of classical sets. From Natural Language to Soft Computing: New Paradigms in Artificial Intelligence / Bucharest, 150-171.

[34] Radojevic, D. (2013). Real-Valued Realizations of Boolean Algebras Are a Natural Frame for Consistent Fuzzy Logic. On Fuzziness: A Homage to Lotfi A. Zadeh / Berlin, 559-565. https://doi.org/10.1007/978-3-642-35644-5_19

[35] Radojevic, D. (2008). Fuzzy Set Theory in Boolean Frame. International Journal of Computers, Communications \& Control, 3, 121-131.

[36] Rakicevic, A., Dobric, V., \& Radojevic, D. (2010). Selection of equity securities with logical aggregation. Foundations and Applications of Computational Intelligence, Procedings of the $9^{\text {th }}$ International FLINS Conference / Chengdu, 603609 https://doi.org/10.1142/9789814324700 0091

[37] Rakicevic, A., Poledica, A., \& Milosevic, P. (2014). Logicbased system for evaluation of corporate financial performance. INFO M, 51, 48-54.

[38] Rakicevic, A., Milosevic, P., Petrovic, B., \& Radojevic, D. (2016). DuPont financial ratio analysis using Logical aggregation. Soft Computing Applications - Advances in Intelligent Systems and Computing, 357 / Berlin, 727-739.

[39] Kostic, J., Bakajac, M., Milosevic, P., \& Poledica, A. (2013). Ranking of Banks Using Logical Aggregation. Proceedings of the 11th Balkan Conference on Operational Research (BALCOR 2013) / Belgrade-Zlatibor, 3-11.

[40] Simeunovic, V., Rakicevic, A., \& Radojevic, D. (2012). Analyzing the effectiveness of measures for energy management in local communities using logical aggregation approach. Proceedings of the $13^{\text {th }}$ International Symposium SymOrg / Zlatibor, 1267-1272.

[41] Jeremic, M., Rakicevic, A., Dragovic, I. (2015). Interpolative Boolean algebra based multi-criteria routing algorithm. Yugoslav Journal of Operations Research, 25(3), 397-412. https://doi.org/10.2298/YJOR140430029J

[42] Poledica, A., Rakicevic, A., \& Radojevic, D. (2012). Multiexpert decision making using logical aggregation. Uncertainty modeling in knowledge engineering and decision making, Proceedings of the $10^{\text {th }}$ International FLINS Conference / Istanbul, 561-566. https://doi.org/10.1142/9789814417747 0090 
[43] Nesic, I., Rakicevic, A., Petrovic, B., Radojevic, D. (2012). Logical aggregation for modular neural networks in currency exchange rate forecasting. Uncertainty modeling in knowledge engineering and decision making, Proceedings of the $10^{\text {th }}$ International FLINS Conference / Istanbul, 573-578. https://doi.org/10.1142/9789814417747_0092

[44] Milosevic, P., Petrovic, B., Radojevic, D., \& Kovacevic, D. (2014). A software tool for uncertainty modeling using Interpolative Boolean algebra. Knowledge-Based Systems, 62, 1-10. https://doi.org/10.1016/j.knosys.2014.01.019

[45] Rakicevic, A., Nesic, I., \& Radojevic, D. (2013). A novel approach to hierarchical clustering based on logical measure of dissimilarity. Proceedings of the $11^{\text {th }}$ Balkan Conference on Operational Research (BALCOR 2013) / BelgradeZlatibor, 147-155.

[46] Everitt, B. S., Landau, S., Leese M., \& Stahl, D. (2011). Cluster Analysis. $5^{\text {th }}$ ed. Chichester: John Wiley \& Sons Ltd. https://doi.org/10.1002/9780470977811

[47] Rakicevic, A., Nesic, I., Radojevic, D., \& Petrovic, B. (2011). Hierarchical clustering using consistent fuzzy technique. Proceedings of XXXVIII Symposium on Operational Research (SYM-OP-IS 2011) / Zlatibor, 418420.

[48] Rakicevic, A. (2012). Logicko klasterovanje - Hijerarhijski pristup. Master teza. Fakultet organizacionih nauka. Beograd.

[49] Radojevic, D. (2005). Interpolative relations and interpolative preference structures. Yugoslav Journal of Operations Research, 15(2), 171-189. https://doi.org/10.2298/YJOR0502171R

[50] Radojevic, D. (2008). Interpolative realization of Boolean algebra as a consistent frame for gradation and/or fuzziness. Forging New Frontiers: Fuzzy Pioneers II / Berlin, 295-317. https://doi.org/10.1007/978-3-540-73185-6_13

[51] Thaler, R. H. (Ed.). (2005). Advances in behavioral finance (Vol. 2). Princeton University Press, New York.

\section{Contact information:}

Aleksandar RAKIĆEVIĆ,

University of Belgrade,

Faculty of Organizational Sciences,

Jove llića 154, 11000 Belgrade, Serbia

E-mail: aleksandar.rakicevic@fon.bg.ac.rs

Dr Vlado SIMEUNOVIĆ, professor

University of Istočno Sarajevo,

Faculty of Education in Bijeljina,

Semberskih ratara bb, 76300 Bijeljina, Bosnia and Herzegovina

E-mail: vlado.simeunovic@pfb.ues.rs.ba

Dr Bratislav PETROVIĆ, professor

University of Belgrade,

Faculty of Organizational Sciences,

Jove llića 154, 11000 Belgrade, Serbia

E-mail: bratislav.petrovic@fon.bg.ac.rs

\section{Sanja MILIĆ}

University of Istočno Sarajevo,

Faculty of Education in Bijeljina,

Semberskih ratara bb, 76300 Bijeljina, Bosnia and Herzegovina

E-mail: sanja.milic@pfb.ues.rs.ba 